Bull. Mater. Sci., Vol. 39, No. 7, December 2016, pp. 1631-1634. (C) Indian Academy of Sciences.

\title{
Crystal structure of the new diamond-like semiconductor $\mathrm{CuMn}_{2} \mathrm{InSe}_{4}$
}

\author{
G E DELGADO ${ }^{1, *}$ and V SAGREDO ${ }^{2}$ \\ ${ }^{1}$ Laboratorio de Cristalografía, Departamento de Química, Facultad de Ciencias, Universidad de Los Andes, \\ Mérida 5101, Venezuela \\ ${ }^{2}$ Laboratorio de Magnetismo en Sólidos, Departamento de Física, Facultad de Ciencias, Universidad de Los Andes, \\ Mérida 5101, Venezuela
}

MS received 8 February 2016; accepted 26 April 2016

\begin{abstract}
The crystal structure of the semiconductor compound $\mathrm{CuMn}_{2} \mathrm{InSe}_{4}$ was analysed using X-ray powder diffraction data. CuMn $\mathrm{InSe}_{4}$ crystallizes, with a stannite structure, in the tetragonal space group I $\overline{4} 2 \mathrm{~m}$ (No. 121), $Z=2$, with unit cell parameters $a=5.8111(2) \AA, c=11.5739(8) \AA$ and $V=390.84(3) \AA^{3}$. The refinement of 28 instrumental and structural parameters led to $R_{\mathrm{p}}=8.1 \%, R_{\mathrm{wp}}=10.5 \%, R_{\exp }=6.5 \%$ and $S=1.6$, for 86 independent reflections.
\end{abstract}

Keywords. Semiconductors; crystal structure; X-ray powder diffraction; Rietveld refinement.

\section{Introduction}

Diluted magnetic semiconductors (DMSs) are of great interest because of their peculiar magnetic and magneto-optical properties arising from the presence of magnetic ions in the lattice [1]. The DMS materials more frequently studied are alloys obtained from the tetrahedrally coordinated derivatives of the II-VI semiconductor family [2]. One of these derivative families are the quaternary semiconductors with formula $\mathrm{I}-\mathrm{II}_{2}-\mathrm{III}-\mathrm{VI}_{4}$ and $\mathrm{I}_{2}-\mathrm{II}-\mathrm{IV}-\mathrm{VI}_{4}$, which belong to the normal compound of fourth derivatives of the II-VI binary semiconductors with three types of cations [3].

Due to the great variety of possible compositions $(\mathrm{I}=\mathrm{Cu}$, $\mathrm{Ag} ; \mathrm{II}=\mathrm{Zn}, \mathrm{Cd}, \mathrm{Mn}, \mathrm{Fe} ; \mathrm{III}=\mathrm{Al}, \mathrm{Ga}$, In; IV = Si, Ge, Sn; VI $=\mathrm{S}, \mathrm{Se}, \mathrm{Te}$ ), these quaternary diamond-like materials can be useful for applications such as tunable semiconductors [4], photovoltaics [5], spintronics [6], non-linear optics [7] and thermoelectrics [8].

In particular, the composition $\mathrm{I}-\mathrm{II}_{2}-\mathrm{III}-\mathrm{VI}_{4}$ can be seen as the addition of a II-VI binary compound to ternary chalcopyrite structures I-III- $\mathrm{VI}_{2}$ to produces alloys of composition (I-III-VI $)_{1-x}$-(II-VI) $)_{x}$ with $x=2 / 3$. Proof of the formation of these types of compounds can be found in the recent literature [9-13]. Structural studies carried out on some members of both families of compounds indicate that they crystallize in a sphalerite derivative structure (stannite) with tetragonal space group $\mathrm{I} \overline{4} 2 \mathrm{~m}$ (No. 121) [14], or in a wurtzite derivative structure (wurtzite-stannite) with orthorhombic space group Pmn2 1 (No. 31) [15].

For the $\mathrm{CuMn}_{2} \mathrm{InSe}_{4}$ quaternary compound, to the best of our knowledge, there are no data on its crystal structure based on single-crystal or powder X-ray diffraction measurements. Only growth and optical properties studies of some

*Author for correspondence (gerzon@ula.ve) compositions for the $\left(\mathrm{CuInSe}_{2}\right)_{1-x}(2 \mathrm{MnSe})_{x}$ alloys have been described $[16,17]$. Therefore, in this work, we report the X-ray powder diffraction data and crystal structure of the quaternary compound $\mathrm{CuMn}_{2} \mathrm{InSe}_{4}$, a new member of the $\mathrm{I}-\mathrm{II}_{2}-\mathrm{III}-\mathrm{VI}_{4}$ family, which crystallizes with a stannite structure. From this study, unit cell parameters, atomic coordinates, isotropic temperature factors and other relevant geometric data can be determined, being of sufficient quality to be included in the PDF-International Centre for Diffraction Data (ICDD) [18] database.

\section{Experimental}

A sample of $\mathrm{CuMn}_{2} \mathrm{InSe}_{4}$ was prepared by melting pure elements $(\mathrm{Cu}, \mathrm{Mn}, \mathrm{In}$ and $\mathrm{Se})$ in evacuated closed silica ampoules at a maximum temperature of $1100^{\circ} \mathrm{C}$. The resultant polycrystalline product was ground and introduced into a new quartz ampoule, $18-\mathrm{cm}$ long, with a suitable amount of $I_{2}$ used as transporting agent. The crystals were grown by placing the ampoule in a two-zone furnace, and keeping the source zone temperature at $1000-950^{\circ} \mathrm{C}$ and the deposition zone temperature $900-875^{\circ} \mathrm{C}$ for 15 days. Finally, the sample was cooled to room temperature at a rate of $10^{\circ} \mathrm{C} \mathrm{h}^{-1}$. The sample was looked at in a microscope; it showed homogeneity in the entire ingot.

The stoichiometric relation of the sample was investigated by SEM technique, using a Hitachi S2500 microscope equipped with a Kedex EDX accessory. Three different regions of the ingot were scanned and the average atomic percentages are as follows: $\mathrm{Cu}(11.0 \%), \mathrm{Mn}(25.3 \%), \mathrm{In}(11.3 \%)$ and $\mathrm{Se}$ $(52.4 \%)$. The error in standardless analysis was around $5 \%$.

For the X-ray analysis, a small quantity of the sample, cut from the ingot, was ground mechanically in an agate mortar and pestle. The resulting fine powder, sieved to $106 \mu \mathrm{m}$, was 
mounted on a flat zero-background holder covered with a thin layer of petroleum jelly. The X-ray powder diffraction data were collected at 293(1) $\mathrm{K}$, in $\theta / \theta$ reflection mode using a Siemens D5005 diffractometer equipped with an X-ray tube (CuK $\alpha$ radiation: $\lambda=1.54059 \AA ; 40 \mathrm{kV}$ and $30 \mathrm{~mA}$ ) and a $\mathrm{Ge}<111>$ primary monochromator. A fixed aperture and divergence slit of $1 \mathrm{~mm}$, a 1-mm monochromator slit and a $0.1-\mathrm{mm}$ detector slit were used. The specimen was scanned from $10^{\circ}$ to $100^{\circ} 2 \theta$, with a step size of $0.02^{\circ}$ and counting time of $40 \mathrm{~s}$. Quartz was used as an external standard.

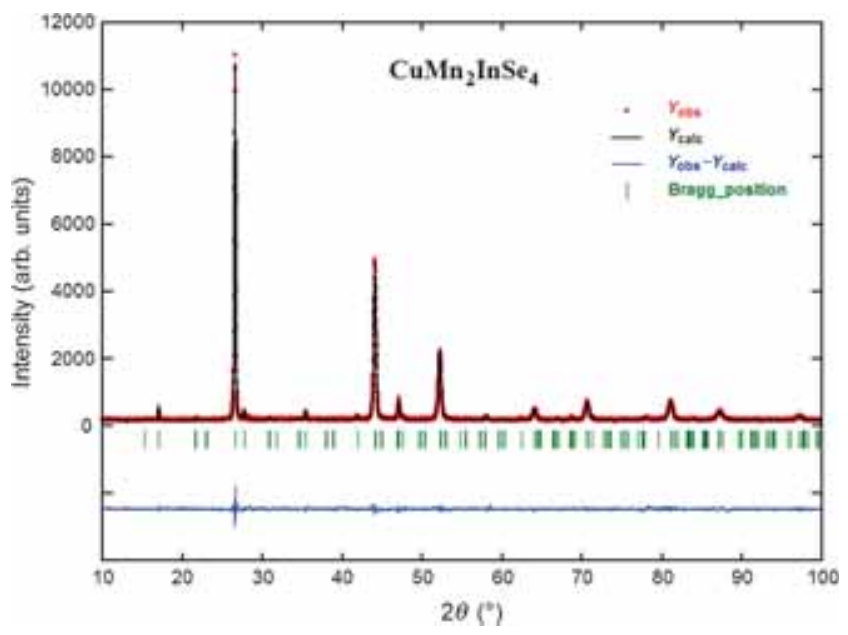

Figure 1. Final Rietveld plot showing the observed, calculated and difference pattern for the $\mathrm{CuMn}_{2} \mathrm{InSe}_{4}$ compound. The Bragg reflections for both phases are indicated by vertical bars.
For pattern indexing and unit cell parameters refinement, the precise determination of peaks positions was carried out by means of the Bruker AXS analytical software.

\section{Results and discussion}

Figure 1 shows the resulting $\mathrm{X}$-ray powder diffractogram for the $\mathrm{CuMn}_{2} \mathrm{InSe}_{4}$ compound. The 20 first peak positions were indexed using the program Dicvol06 [19], which gave a unique solution in a tetragonal cell. The systematic absences study ( $h k l: h+k+l=2 n)$ indicated an I-type cell. A revision of the diffraction lines taking into account the sample composition, unit cell parameters as well as the body centre cell suggested that this material is isostructural with $\mathrm{CuFe}_{2} \mathrm{InSe}_{4}$ [10], the first compound of the $\mathrm{I}-\mathrm{II}_{2}-\mathrm{III}-\mathrm{VI}_{4}$ family with a stannite structure, which crystallizes in the tetragonal space group $\mathrm{I} \overline{4} 2 \mathrm{~m}$ (No. 121).

The complete powder diffraction data set was reviewed in the tetragonal space group $\mathrm{I} \overline{4} 2 \mathrm{~m}$ using the program NBS* AIDS83 [20]. From this analysis, the refined unit cell parameters obtained were $a=5.8103(4) \AA$ and $c=11.5749(8) \AA$, with figures of merit $M_{20}=69.4$ [21] and $F_{23}=35.4$ $(0.0089,73)$ [22]. The resulting X-ray powder diffraction data for $\mathrm{CuMn}_{2} \mathrm{InSe}_{4}$, together with the observed and calculated $2 \theta$, the $d$-spacings as well as the relative intensities of the reflections, are given in table 1 . These data will be submitted to the Powder Diffraction File of the ICDD [18].

The Rietveld refinement [23] of the whole diffraction pattern was carried out using the Fullprof program [24], with the

Table 1. X-ray powder diffraction data of $\mathrm{CuMn}_{2} \mathrm{InSe}_{4}$.

\begin{tabular}{rrrrrrrrr}
\hline $2 \theta_{\text {obs }}\left({ }^{\circ}\right)$ & $d_{\text {obs }}(\AA)$ & $\left(I / I_{\mathrm{o}}\right)_{\text {obs }}$ & $h$ & $k$ & $l$ & $2 \theta_{\text {cal }}\left({ }^{\circ}\right)$ & $d_{\text {cal }}(\AA)$ & $\Delta 2 \theta\left(^{\circ}\right)$ \\
\hline 17.062 & 5.1923 & 4.2 & 1 & 0 & 1 & 17.060 & 5.1928 & -0.002 \\
21.605 & 4.1096 & 1.9 & 1 & 1 & 0 & 21.611 & 4.1085 & 0.006 \\
26.581 & 3.3506 & 100.0 & 1 & 1 & 2 & 26.584 & 3.3502 & 0.003 \\
27.726 & 3.2147 & 4.0 & 1 & 0 & 3 & 27.731 & 3.2142 & 0.004 \\
30.903 & 2.8911 & 2.0 & 0 & 0 & 4 & 30.874 & 2.8937 & -0.029 \\
34.511 & 2.5966 & 3.5 & 2 & 0 & 2 & 34.514 & 2.5964 & 0.003 \\
35.361 & 2.5361 & 1.8 & 2 & 1 & 1 & 35.373 & 2.5353 & 0.011 \\
41.886 & 2.1549 & 2.9 & 2 & 1 & 3 & 41.879 & 2.1552 & -0.007 \\
44.133 & 2.0503 & 44.7 & 2 & 0 & 4 & 44.135 & 2.0502 & 0.002 \\
47.060 & 1.9294 & 7.5 & 0 & 0 & 6 & 47.065 & 1.9292 & 0.005 \\
49.567 & 1.8375 & 2.0 & 3 & 1 & 0 & 49.570 & 1.8374 & 0.003 \\
52.185 & 1.7513 & 20.4 & 3 & 1 & 2 & 52.186 & 1.7512 & 0.001 \\
57.942 & 1.5902 & 3.7 & 1 & 0 & 7 & 57.934 & 1.5904 & -0.008 \\
59.540 & 1.5513 & 3.1 & 3 & 1 & 4 & 59.548 & 1.5511 & 0.008 \\
64.058 & 1.4524 & 4.2 & 4 & 0 & 0 & 64.047 & 1.4526 & -0.010 \\
64.338 & 1.4467 & 4.6 & 0 & 0 & 8 & 64.330 & 1.4469 & -0.008 \\
68.691 & 1.3653 & 2.6 & 1 & 1 & 8 & 68.722 & 1.3647 & 0.031 \\
70.640 & 1.3323 & 6.6 & 3 & 3 & 2 & 70.615 & 1.3327 & -0.024 \\
71.232 & 1.3227 & 2.6 & 3 & 2 & 5 & 71.236 & 1.3226 & 0.005 \\
79.559 & 1.2038 & 2.1 & 4 & 1 & 5 & 79.568 & 1.2037 & 0.009 \\
81.053 & 1.1854 & 6.7 & 4 & 2 & 4 & 81.064 & 1.1852 & 0.011 \\
87.481 & 1.1141 & 4.0 & 1 & 1 & 10 & 87.474 & 1.1141 & -0.007 \\
97.428 & 1.0250 & 2.3 & 4 & 0 & 8 & 97.422 & 1.0251 & -0.006 \\
\hline & & & & & & & & \\
\hline
\end{tabular}


Table 2. Rietveld refinement details for $\mathrm{CuMn}_{2} \mathrm{InSe}_{4}$.

\begin{tabular}{llll}
\hline Molecular formula & $\mathrm{CuMn}_{2} \mathrm{InSe}_{4}$ & Molecular weight $\left(\mathrm{g} \mathrm{mol}^{-1}\right)$ & 604.1 \\
$a(\AA)$ & $5.8111(2)$ & Space group & $\mathrm{I} 4 \overline{2} \mathrm{~m}($ No. 121) \\
$c(\AA)$ & $11.5739(8)$ & $Z$ & 2 \\
$V\left(\AA^{3}\right)$ & $390.84(2)$ & $D_{\text {calc }}\left(\mathrm{g} \mathrm{cm}^{-3}\right)$ & 5.13 \\
$R_{\exp }(\%)=6.5$ & $R_{\mathrm{p}}(\%)=8.1$ & $R_{\mathrm{wp}}(\%)=10.5$ & $S=1.6$ \\
\hline
\end{tabular}

$R_{\mathrm{p}}=100 \sum\left|y_{\mathrm{obs}}-y_{\text {calc }}\right| / \sum\left|y_{\mathrm{obs}}\right|, R_{\mathrm{wp}}=100\left[\sum_{\mathrm{w}}\left|y_{\mathrm{obs}}-y_{\mathrm{calc}}\right|^{2} / \sum_{\mathrm{w}}\left|y_{\mathrm{obs}}\right|^{2}\right]^{1 / 2}$, $S=\left[R_{\mathrm{wp}} / R_{\exp }\right] R_{\exp }=100\left[(N-P+C) / \sum_{\mathrm{w}}\left(y_{\mathrm{obs}}^{2}\right)\right]^{1 / 2}, N-P+C$ is the number of degrees of freedom.

Table 3. Unit cell, atomic coordinates, isotropic temperature factor and selected geometric parameters $\left(\AA,^{\circ}\right)$ for $\mathrm{CuMn}_{2} \mathrm{InSe} 4$.

\begin{tabular}{|c|c|c|c|c|c|c|c|c|}
\hline Atom & Ox. & BVS & Wyck. & $x$ & $y$ & $z$ & $F_{\mathrm{oc}}$ & $B\left(\AA^{2}\right)$ \\
\hline $\mathrm{Cu}$ & +1 & 1.3 & $2 a$ & 0 & 0 & 0 & 1 & $0.67(5)$ \\
\hline $\mathrm{Mn}$ & +2 & 2.3 & $4 d$ & 0 & $1 / 2$ & $1 / 4$ & 1 & $0.67(5)$ \\
\hline In & +3 & 3.0 & $2 b$ & 0 & 0 & $1 / 2$ & 1 & $0.67(5)$ \\
\hline $\mathrm{Se}$ & -2 & 2.2 & $8 i$ & $0.2390(5)$ & $0.2390(5)$ & $0.1261(6)$ & 1 & $0.67(5)$ \\
\hline $\mathrm{Cu}-\mathrm{Se}^{\mathrm{i}}$ & $2.447(5)$ & & $\mathrm{Mn}-\mathrm{Se}$ & $2.507(5)$ & & In-Se & $2.594(5)$ & \\
\hline $\mathrm{Se}^{\mathrm{ii}}-\mathrm{Cu}-\mathrm{Se}^{\mathrm{iii}}$ & $110.8(1)$ & $x 4$ & $\mathrm{Se}-\mathrm{Mn}-\mathrm{Se}^{\mathrm{iv}}$ & 109.1(1) & $x 4$ & $\mathrm{Se}-\mathrm{In}-\mathrm{Se} \mathrm{vi}^{\mathrm{vi}}$ & $108.5(1)$ & $x 4$ \\
\hline $\mathrm{Se}^{\mathrm{i}}-\mathrm{Cu}-\mathrm{Se}^{\mathrm{iii}}$ & $106.8(1)$ & $x 2$ & $\mathrm{Se}-\mathrm{Mn}-\mathrm{Se}^{\mathrm{v}}$ & $110.2(1)$ & $x 2$ & $\mathrm{Se}^{\mathrm{vii}-\mathrm{In}-\mathrm{Se}}$ & 111.5(1) & $x 2$ \\
\hline
\end{tabular}

Symmetry codes:

(i) $-0.5+x,-0.5+y, 0.5+z$; (ii) $-y, x,-z$; (iii) $-x,-y, z$; (iv) $-0.5+y, 0.5-x, 0.5-z$; (v) $-x, 1-y, z$; (vi) $0.5-y,-0.5+x, 0.5-z$. Bond valence sum (BVS): $V_{i}=\sum_{j} \exp \left[\left(R_{\mathrm{O}}-R_{i j}\right) / b\right], b=0.37 \AA, r_{\mathrm{o}}(\mathrm{Cu}-\mathrm{Se})=2.02 \AA, r_{\mathrm{o}}(\mathrm{Mn}-\mathrm{Se})=2.32 \AA, r_{\mathrm{o}}(\mathrm{In}-\mathrm{Se})=2.47 \AA$.

unit cell parameters are presented below. The atomic coordinates of the compound $\mathrm{CuFe}_{2} \mathrm{InSe}_{4}$ [10] were used as the initial model for the refinement of $\mathrm{CuMn}_{2} \mathrm{InSe}_{4}$; the cation distribution is shown in table 2. The angular dependence of the peak full-width at half-maximum (FWHM) was described by the Caglioti formula [25]. Peak shapes were described by the parameterized Thompson-Cox-Hastings pseudo-Voigt profile function [26]. The background variation was described by a polynomial with six coefficients. The thermal motion of the atoms was described by one overall isotropic temperature factor.

The results of the Rietveld refinement are summarized in table 2. Figure 1 shows the observed calculated and difference profile for the final cycle of Rietveld refinement. Atomic coordinates, isotropic temperature factor, bond distances and angles are shown in table 3 . This table also shows the bond valence sum (BVS) $[27,28]$ results for $\mathrm{CuMn}_{2} \mathrm{InSe}_{4}$, indicating that the oxidation state for each ion is in good agreement with the expected formal oxidation state of $\mathrm{Cu}^{1+}, \mathrm{Mn}^{2+}, \mathrm{In}^{3+}$ and $\mathrm{Se}^{2-}$ ions.

$\mathrm{CuMn}_{2} \mathrm{InSe}_{4}$ is a normal adamantane-structure compound and can be described as a derivative of the sphalerite structure [2]. Figure 2 shows the unit cell diagram for this compound. The tetrahedrons containing the $\mathrm{Cu}$ atoms [mean Se...Se distance $3.95(6) \AA]$ are slightly smaller than those containing the Mn atoms [mean Se...Se distance 4.094(6) $\AA$ ] and In atoms [mean Se...Se distance 4.237(6) ̊̊]. The bond

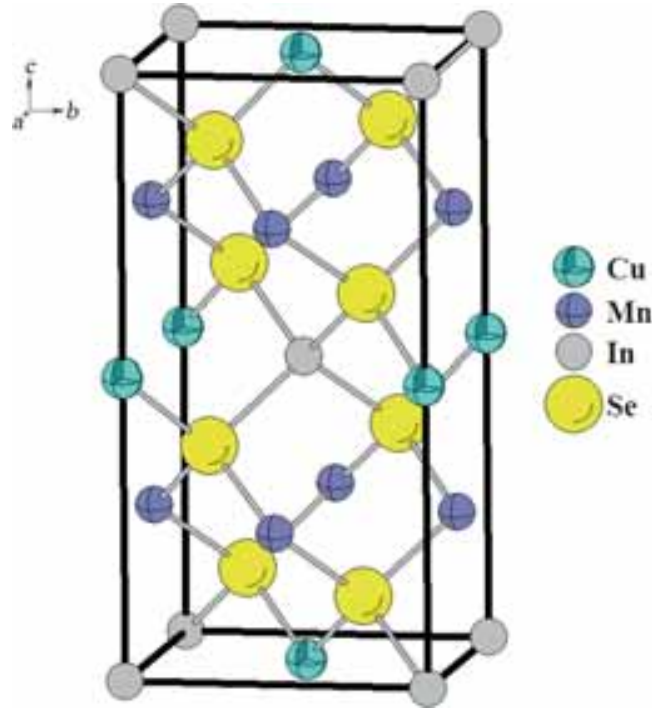

Figure 2. Unit cell diagram for the $\mathrm{CuMn}_{2} \mathrm{InSe}_{4}$ phase.

distances of $\mathrm{Cu}-\mathrm{Se}$ [2.447(5) $\AA$ ], Mn-Se [2.507(5) $\AA$ ] and In-Se [2.594(5) $\AA]$ are in good agreement with those observed in other adamantane quaternary compounds found in the ICSD database [29] such as $\mathrm{CuFe}_{2} \mathrm{InSe}_{4}$ [10], CuFeInSe [30], $\mathrm{Cu}_{2} \mathrm{FeSnSe}_{4}$ [31] and $\mathrm{Cu}_{2} \mathrm{MnSnSe}_{4}$ [32]. 


\section{Conclusions}

The refinement of the crystal structure of the semiconductor $\mathrm{CuMn}_{2} \mathrm{InSe}_{4}$ by the Rietveld method from X-ray powder diffraction data indicated that this compound crystallizes in the tetragonal space group $\bar{I} \overline{4} 2 \mathrm{~m}$ with a stannite structure and represents a new semiconductor of the family $\mathrm{I}-\mathrm{II}_{2}-\mathrm{III}-\mathrm{VI}_{4}$.

\section{Acknowledgement}

This work was supported by CDCHTA-ULA (Grant C-165809-05-A) and FONACIT (Grant LAB-97000821).

\section{References}

[1] Nikiforov K G 1999 Progr. Cryst. Growth Charact. Mater. 39 1

[2] Parthé E, Yvon K and Deitch R H 1969 Acta Crystallogr. B 251164

[3] Delgado J M 1998 Inst. Phys. Conf. Ser. 15245

[4] Ford G M, Guo Q, Agrawal R, Hillhouse H W and Hugh W 2011 Chem. Mater. 232626

[5] Guo Q, Ford G M, Yang W C, Walker B C, Stach E A, Hillhouse H W and Agrawal R 2010 J. Am. Chem. Soc. 132 17384

[6] Chambers S A and Yoo Y K 2003 MRS Bull. 28706

[7] Li Y, Fan W, Sun H, Cheng X, Li P and Zhao X 2011 J. Phys.: Condens. Matter 23225401

[8] Sevik C and Ca T 2010 Phys. Rev. B 82045202

[9] Grima-Gallardo P, Muñoz M, Durán S, Quintero M, Quintero E, Morocoima M, Calderón E, Delgado G E and Romero H 2008 Phys. Status Solidi (a) 2051552

[10] Delgado G E, Mora A J, Grima-Gallardo P and Quintero M 2008 J. Alloys Compd. $\mathbf{4 5 4} 306$
[11] Delgado G E, Mora A J, Grima-Gallardo P, Durán S, Muñoz M and Quintero M 2008 Physica B 4033228

[12] Delgado G E, Quintero E, Tovar R, Grima-Gallardo P and Quintero M 2014 J. Alloys Compd. 613143

[13] Delgado G E, Mora A J, Grima-Gallardo P, Muñoz M, Durán S, Quintero M and Briceño J M 2015 Bull. Mater. Sci. 381061

[14] Hall S R, Szymanski J T and Stewart J M 1978 Can. Mineral. 16131

[15] Parthé E, Yvon K and Deitch R H 1969 Acta Crystallogr. B 251164

[16] Bodnar V 2009 Inorg. Mater. 45352

[17] Bodnar V 2010 Semiconductors 44581

[18] 2013 PDF-powder diffraction file (set 1-65) (Newtown Square, PA, USA: International Centre for Diffraction Data)

[19] Boultif A and Löuer D 2004 J. Appl. Crystallogr. 37724

[20] Mighell A D, Hubbard C R and Stalick J K, National Bureau of Standards, Tech. Note 11411981

[21] Smith G S and Snyder R L 1979 J. Appl. Crystallogr. 1260

[22] Wolff de P M 1968 J. Appl. Crystallogr. 1108

[23] Rietveld H M 1969 J. Appl. Crystallogr. 265

[24] Rodriguez-Carvajal J 1993 Physica B 19255

[25] Cagliotti G, Paoletti A and Ricci F P 1958 Nucl. Instrum. 3223

[26] Thompson P, Cox D E and Hastings J B 1987 J. Appl. Crystallogr. 2079

[27] Brown I D and Altermatt D 1985 Acta Crystallogr. B 41244

[28] Brese N E and O'Keeffe M 1991 Acta Crystallogr. 47987

[29] 2008 ICSD — inorganic crystal structure database (Kalrsruhe, Germany: Gemlin Institute) (set 2008-02)

[30] Mora A J, Delgado G E and Grima-Gallardo P 2007 Phys. Status Solidi (a) 204547

[31] Roque-Infante E, Delgado J M and López-Rivera S A 1997 Mater. Lett. 3367

[32] Sachanyuk V P, Olekseyuk I D and Parasyuk O V 2006 Phys. Status Solidi (a) 203459 